Relations industrielles

Industrial Relations

\title{
Annexe II : Bibliographie
}

Volume 27, numéro 1-2, 1972

Vocabulaire français-anglais des relations professionnelles

Glossary of Terms used in Industrial Relations (English-French)

URI : https://id.erudit.org/iderudit/028304ar

DOI : https://doi.org/10.7202/028304ar

Aller au sommaire du numéro

Éditeur(s)

Département des relations industrielles de l'Université Laval

\section{ISSN}

0034-379X (imprimé)

1703-8138 (numérique)

Découvrir la revue

Citer ce document

(1972). Annexe II : Bibliographie. Relations industrielles / Industrial Relations,

27(1-2), 299-302. https://doi.org/10.7202/028304ar

Tous droits réservés (C) Département des relations industrielles de l'Université Laval, 1972
Ce document est protégé par la loi sur le droit d'auteur. L’utilisation des services d'Érudit (y compris la reproduction) est assujettie à sa politique d'utilisation que vous pouvez consulter en ligne.

https://apropos.erudit.org/fr/usagers/politique-dutilisation/ 


\section{Annexe II}

BIBLIOGRAPHIE

AVIS, W.S., DRYSDALE, P.D., GREGG, R.J. and SCORGILL, M.H., Dictionary of Canadian English - The Senior Dictionary, Scarborough, Ont., W.J. Wage Limited, 1967, $1284 \mathrm{pp}$.

BAILLY, René, Dictionnaire des synonymes de la langue française, Paris, Librairie Larousse, 1947, $626 \mathrm{pp}$.

BAUDHUIN, Fernand, Dictionnaire de l'économie contemporaine, Paris, Marabout service. Economie moderne, 1968, 301 pp.

BELISLE, Louis-A., Petit dictionnaire canadien de la langue française, Montréal, Les Editions Aries, 1969, 644 pp.

BENAC, Henri, Dictionnaire des synonymes, Paris, Librairie Hachette, 1956. $1026 \mathrm{pp}$.

BIROU, Alain, Vocabulaire pratique des sciences sociales, Paris, Economie et humanisme. Les Editions Ouvrières, 1966, 314 pp.

BOISSONNAT, Jean, Petite encyclopédie politique, Paris, Seuil, 1969, 301 pp.

CASSELMAN, P.H., Labor Dictionary, New York, Philosophical Library, 1949, $541 \mathrm{pp}$.

CHARTIER, Roger, Répertoire alphabétique des matières de relations industrielles, Québec, Département des relations industrielles. Faculté des sciences sociales, Université Laval, mars 1962, 169 pp.

COLPRON, Gilles, Les anglicismes au Québec, Montréal, Librairie Beauchemin Ltée, 1970, $247 \mathrm{pp}$.

DAGENAIS, Gérard, Dictionnaire des difficultés de la langue française au Canada, Montréal, Editions Pedagogia Inc., 1967, 679 pp.

DOHERTY, Robert E., Industrial and Labor Relations Terms, Ithaca, N.Y., New York State School of Industrial and Labor Relations, Cornell University, 1962. $32 \mathrm{pp}$.

DULONG, Gaston, Dictionnaire correctif du français au Canada, Québec, P.U.L., 1968, 255 pp.

FERGUSON. Roberg H., Wages, Earnings and Incomes: Definition of Terms and Sources of Data, Bulletin 63, Ithaca, N.Y., New York State School of Industrial and Labor Relations, Cornell University, 1971,65 pp. 
GILPIN, Alan, Dictionary of Economic Terms, London, Butterworths, 1966. $222 \mathrm{pp}$.

GUILHAUMOU. J., Lexique de l'information, Paris, Entreprise moderne d'édition, 1969, $121 \mathrm{pp}$.

LAMBERT, Denis-Clair, Terminologie économique et monétaire, (Initiation économique), Paris, Economie et Humanisme, Les Editions Ouvrières, 1970. $326 \mathrm{pp}$.

LAUZEL, P., Lexique de la gestion, Paris, Entreprise moderne d'édition, 1970. $237 \mathrm{pp}$.

LEBEL, Wilfrid, Le dictionnaire des affaires, Montréal, les Editions de l'Homme, 1967, 77 pp.

LEMEUNIER, Francis, Dictionnaire juridique, économique et financier, Paris, Editions J. Delmas et Cie., 1969, 366 pp.

MALIGNON, Jean, Dictionnaire de politique, Paris, Editions Cujas, 1967, 455 pp.

MAQUET, Charles, Dictionnaire analogique, Paris, Librairie Larousse, 1936. $591 \mathrm{pp}$.

MUCHIELLI, A et R., Lexique de la psychologie, Paris, Entreprise moderne d'édition. Editions sociales françaises, 1969, 184 pp.

MUCHIELLI, A et R., Lexique des sciences sociales, Paris, Entreprise moderne d'édition. Editions sociales françaises, 1969, 196 pp.

PERON, Michel, Dictionnaire français anglais - anglais français des affaires, Paris, Librairie Larousse, 1968, 246 pp.

PUJOL, Rosemonde, Petit dictionnaire de l'économie, Paris, Denoël/Gonthier. 1970, $254 \mathrm{pp}$.

ROBERT, Paul, Dictionnaire alphabétique et analogique de la langue française, Paris, Presses universitaires de France, 1953-1965, (6 volumes).

ROBERTS, Harold S., Roberts' Dictionary of Industrial Relations, Washington. BNA Books, 1966, 486 pp.

ROMEUF, Jean, Dictionnaire des sciences économiques, 2 vol., Paris, P.U.F., 1956.

SERVOTTE, J.V., Dictionnaire commercial et financier, Paris, Marabout service, 1963, $446 \mathrm{pp}$. 
SUAVET, Thomas, Dictionnaire économique et social, (initiation économique), Paris, Economie et Humanisme, Les Editions ouvrières, 1962, 453 pp.

TEZENAS, J., Dictionnaire de l'organisation et de la gestion, Paris, Les Editions d'organisation, 1968, $233 \mathrm{pp}$.

THOMAS, Adolphe V., Dictionnaire des difficultés de la langue française, Paris, Librairie Larousse, 1971, 435 pp.

VAUGHAN, Clifford F. and M., Glossary of Economics in English, Americain, French, German, Russian, Paris, Dunod, 1966, 201 pp.

Canadianismes de bon aloi, Québec, Office de la langue française, Hôtel du gouvernement, (diffusion du français - no 1), 1970, $11 \mathrm{pp}$.

Dictionnaire anglais-français, La Division Howard Smith, Domtar Pulp and Paper Limited, 1948, 194 pp.

Glossaire des termes medico-hospitaliers, par le Comité d'étude des termes de médecine. Québec. Office de la langue française. Hôtel du gouvernement. $1968,50 \mathrm{pp}$.

Glossaires bilingues de la terminologie américaine. Ambassade de France aux Etats-Unis, Le Conseiller Commercial, Service d'Analyse Industrielle, 2 e édition. $183 \mathrm{pp}$.

Glossario Del Lavoro, Milano, Associazone Industriale Lombarda, 1964, 1335 $\mathrm{pp}$.

Guide du journaliste, Montréal, La Presse Canadienne, 1969, 127 pp.

Harrap's Standard French and English Dictionary, London, Toronto, Wellington, Sydney, George G. Harrap \& Company, Ltd., 1965, (2 volumes).

Labour Terms Canadian, Don Mills, ONT., CCH Canadian Limited, 1962, 94 pp.

Lexique, Québec, Assemblée nationale, Journal des Débats, 5 e édition, mai 1970, 138 pp.

Lexique des principaux termes marxistes, par l'Institut Confédéral d'études et de formation C.F.D.T. (C.F.T.C.), Formation, nouvelle série, 23 e année, no 90. nov-déc. 1970, 79 pp.

Liste commune des descripteurs, Paris, O.C.D.E., Développement économique et social, 1969, $307 \mathrm{pp}$.

Organisation industrielle. Ambassade de France aux Etats-Unis, Le Conseiller Commercial, Service D'Analyse Industrielle, 3e édition, 125 pp. 
Répertoire des termes et expressions utilisés en relations industrielles et dans des domaines connexes, Ottawa, Direction de l'Economique et des Fiecherches, Ministère du travail du Canada, 1967, 206 pp.

Vocabulaire des assurances sur la vie, Québec, Office de la langue française. Hôtel du gouvernement, 1970, no 2, 14 pp.

Vocabulaire des élections, Québec, Cahiers de l'Office de la langue française, no 5. Hôtel du gouvernement, 1970, 36 pp.

Vocabulaire des termes bancaires (anglais-français), Banque Royale, 1971, 9 pp.

Webster's Seventh New Dictionary, Springfield, Massachusetts, G. (and) C. Meniam Company, 1971, 1221 pp.

A Standard List of Subject Headings in Industrial Relations, Princeton, New Jersey, Industrial Relations Section, Princeton University, second edition, 1963, $136 \mathrm{pp}$.

Terminologie française dans les relations du travail, chronique publiée de mai 1964 à juin 1968 dans Québec-Travail, Ministère du travail du Québec, Québec.

Fiches du Canadian National, mai, juin 1970.

Fiches linguistiques de Radio-Canada.

Québec, le 18 février, 1972 